\title{
Commentary: Alive without a pulse and bleeding
}

\author{
Zaid M. Abdelsattar, MD, MS, John M. Stulak, MD, and Juan A. Crestanello, MD
}

\author{
From the Department of Cardiovascular Surgery, Mayo Clinic, Rochester, Minn. \\ Disclosures: Authors have nothing to disclose with regard to commercial support. \\ Received for publication April 7, 2019; accepted for publication April 8, 2019; available ahead of print May 21, \\ 2019. \\ Address for reprints: Juan A. Crestanello, MD, Department of Cardiovascular Surgery, Mayo Clinic, 200 First St \\ SW, Rochester, MN 55905 (E-mail: crestanello.juan@mayo.edu). \\ J Thorac Cardiovasc Surg 2020;159:916-7 \\ $0022-5223 / \$ 36.00$ \\ Copyright (C) 2019 by The American Association for Thoracic Surgery \\ https://doi.org/10.1016/j.jtcvs.2019.04.023
}

Arterial pulse has been a sign of life and disease since ancient times. Although its absence is used to diagnose death, many diseases are also associated with characteristic changes in arterial pulse. ${ }^{1}$ The advent of continuous-flow left ventricular assist devices (LVADs) has defied longheld assumptions and established a new normal for these patients: absence of pulse is no longer synonymous with death. Continuous-flow LVADs have revolutionized the management of patients with end-stage heart failure, but they expose patients to chronic nonpulsatile arterial flow. Continuous-flow LVADs have traded pulsatile flow for improved survival and quality of life. Chronic exposure to continuous flow with lack of arterial pulsatility, however, leads to profound hemodynamic and physiologic changes. None of them is more puzzling, disabling, and potentially life-threatening than lower gastrointestinal tract bleeding. As many as $40 \%$ of patients with continuous-flow LVADs have gastrointestinal bleeding develop as a result of angiodysplasias. ${ }^{2-4}$ The mechanisms underlying gastrointestinal bleeding in continuous-flow LVAD are reviewed in this issue of the Journal by Hydren and colleagues. ${ }^{5}$ Acquired von Willebrand factor (vWF) deficiency and the associated platelet dysfunction play a central role in the pathophysiology of gastrointestinal bleeding in patients receiving continuous-flow LVAD support. Hydren and colleagues 5 describe a "double whammy" effect of continuous-flow LVADs through which they lead to impaired vWFdependent platelet aggregation: (1) decreased production of vWF by platelets and endothelial cells and (2) increased degradation of vWF. Although gastrointestinal bleeding in these patients is undoubtedly multifactorial, we would like to highlight a recently identified mechanism that further links vWF deficiency to gastrointestinal bleeding. ${ }^{6}$ The imbalance between vWF multimers (low) and vWF degradation fragments (high) may stimulate angiogenesis through a direct proangiogenic effect. In a recent study, Bartoli and associates ${ }^{6}$ demonstrated that patients with continuous-flow LVAD support who had angiodysplasias and gastrointestinal bleeding had lower levels of vWF multimers and higher levels of vWF degradation fragments. tinal bleeding. ${ }^{6-8}$

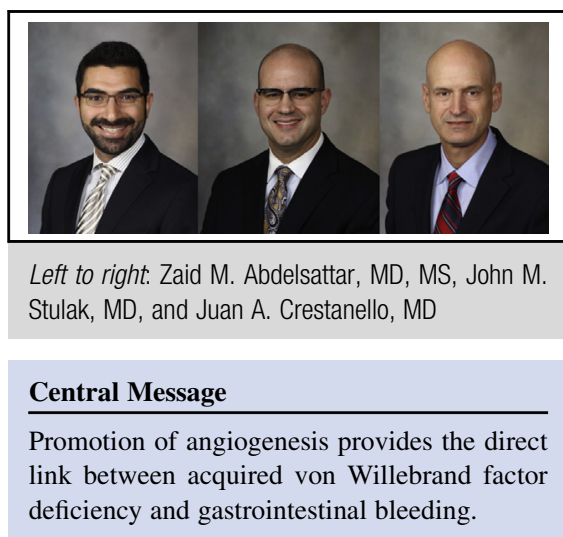

See Article page 910.

Bartoli and associates ${ }^{6}$ also showed that in vitro exposure of endothelial cells to vWF degradation fragments or to plasma from patients receiving LVAD support resulted in abnormal angiogenesis. This proangiogenic mechanism of vWF degradation fragments may be the factor linking shear stress, lack of pulsatility, angiodysplasias, and gastrointes-

Acquired vWF deficiency and gastrointestinal bleeding are not unique to patients receiving continuous-flow LVAD support. These conditions have also been described in patients with valvular heart disease (aortic and mitral stenosis, regurgitant valve lesions, and structural and nonstructural valve deterioration), congenital heart disease, and pulmonary hypertension. ${ }^{7-9}$ The severity of acquired vWF deficiency increases as these lesions progress and usually reverses after treatment either by surgery or by transcatheter procedures. $^{7-9}$

Similar to the conditions in valvular heart disease, preventing the development of acquired vWF deficiency by restoring pulse pressure and decreasing shear stress may lead to lower rates of gastrointestinal bleeding. ${ }^{5}$ Furthermore, advances in hemocompatibility, pump design and management may similarly achieve this goal. The work of Hydren and colleagues ${ }^{5}$ reminds us of the enormous progress that has been achieved in our understanding of gastrointestinal bleeding after continuous-flow LVAD, but it also demonstrates that there are still many unanswered questions. (1) What are the molecular mechanism that explain the different penetrance of gastrointestinal bleeding and angiodysplasias in patients receiving continuous-flow LVAD support? (2) Why do some angiodysplasias bleed and others do not? (3) How much pulsatile flow is necessary to prevent acquired vWF? The answers to these and many other 
questions will improve the safety of continuous-flow LVADs and the quality of life of our patients. Meanwhile, patients supported with continuous-flow LVADs are alive without a pulse at the expense of a higher rate of gastrointestinal bleeding.

\section{References}

1. Ghasemzadeh N, Zafari AM. A brief journey into the history of the arterial pulse. Cardiol Res Pract. 2011;2011:164832.

2. Wever-Pinzon O, Selzman CH, Drakos SG, Saidi A, Stoddard GJ, Gilbert EM, et al. Pulsatility and the risk of nonsurgical bleeding in patients supported with the continuous-flow left ventricular assist device HeartMate II. Circ Heart Fail. 2013;6:517-26.

3. Draper KV, Huang RJ, Gerson LB. GI bleeding in patients with continuous-flow left ventricular assist devices: a systematic review and meta-analysis. Gastrointest Endosc. 2014;80:435-46.e1.
4. Harvey L, Holley CT, John R. Gastrointestinal bleed after left ventricular assist device implantation: incidence, management, and prevention. Ann Cardiothorac Surg. 2014;3:475-9.

5. Hydren JR, Richardson RS, Wever-Pinzon O, Drakos SD. The "double whammy" of a continuous-flow left ventricular assist device on von Willebrand factor. $J$ Thorac Cardiovasc Surg. 2020;159:910-5.

6. Bartoli CR, Zhang DM, Hennessy-Strahs S, Kang J, Restle DJ, Bermudez C, et al. Clinical and in vitro evidence that left ventricular assist device-induced von Willebrand factor degradation alters angiogenesis. Circ Heart Fail. 2018; 11:e004638.

7. Van Belle E, Vincent F, Rauch A, Casari C, Jeanpierre E, Loobuyck V, et al. von Willebrand factor and management of heart valve disease: JACC review topic of the week. J Am Coll Cardiol. 2019;73:1078-88.

8. Loscalzo J. From clinical observation to mechanism-Heyde's syndrome. N Engl J Med. 2012;367:1954-6.

9. Horiuchi H, Doman T, Kokame K, Saiki Y, Matsumoto M. Acquired von Willebrand syndrome associated with cardiovascular diseases. J Atheroscler Thromb. 2019;26:303-14. 